\title{
Predicting Invasions of North American Basses in Japan Using Native Range Data and a Genetic Algorithm
}

\author{
KEI'ICHIRO IGUCHI ${ }^{1}$ \\ National Research Institute of Fisheries Science, \\ Ueda, Nagano 386-0031, Japan \\ KeIICHI MATSUURA \\ National Science Museum, Shinjuku, Tokyo 169-0073, Japan \\ Kristina M. McNyset and A. Townsend Peterson \\ Biodiversity Research Center, University of Kansas, \\ Department of Ecology and Evolutionary Biology, Lawrence, Kansas 66045, USA \\ RicARdo ScACHETTI-PEREIRA ${ }^{2}$ \\ Centro de Referência em Informação Ambiental, \\ Avenida Romeu Tórtima 388, 13084-520 Campinas, São Paulo, Brazil \\ Katherine A. Powers, Dave A. Vieglais, and E. O. Wiley* \\ Biodiversity Research Center, University of Kansas, \\ Department of Ecology and Evolutionary Biology, Lawrence, Kansas 66045, USA \\ TAIGA YOdO ${ }^{3}$ \\ Japan Science and Technology Corporation, Ueda, Nagano 386-0031, Japan
}

\begin{abstract}
Largemouth bass Micropterus salmoides and smallmouth bass M. dolomieu have been introduced into freshwater habitats in Japan, with potentially serious consequences for native fish populations. In this paper we apply the technique of ecological niche modeling using the genetic algorithm for rule-set prediction (GARP) to predict the potential distributions of these two species in Japan. This algorithm constructs a niche model based on point occurrence records and ecological coverages. The model can be visualized in geographic space, yielding a prediction of potential geographic range. The model can then be tested by determining how well independent point occurrence data are predicted according to the criteria of sensitivity and specificity provided by receiver-operator curve analysis. We ground-truthed GARP's ability to forecast the geographic occurrence of each species in its native range. The predictions were statistically significant for both species $(P<0.001)$. We projected the niche models onto the Japanese landscape to visualize the potential geographic ranges of both species in Japan. We tested these predictions using known occurrences from introduced populations of largemouth bass, both in the aggregate and by habitat type. All analyses robustly predicted known Japanese occurrences $(P<0.001)$. The number of smallmouth bass in Japan was too small for statistical tests, but the 10 known occurrences were predicted by the majority of models.
\end{abstract}

Assessing the threat of species invasions and the possible spread of such species is a global challenge that requires a global perspective (Carlton

\footnotetext{
* Corresponding author: ewiley@ku.edu.

${ }^{1}$ Order of authorship is alphabetical, reflecting the collaborative nature of this paper.

2 Present address: Biodiversity Research Center, University of Kansas, Lawrence, Kansas 66045, USA.

3 Present address: Department of Life Science, Faculty of Bioresources, Mie University, 1515 Kamihama, Tsu, Mie 514-8507, Japan.
}

Received October 9, 2003; accepted December 3, 2003
1996; Enserink 1999). To achieve this perspective, we can apply analytical tools and use information on ecological landscapes that can be gathered on a global scale as well as specimen records to seek the sets of factors that are useful in forecasting places where the establishment of species is possible. The point is not necessarily to learn more about the ecology of the species-this would require detailed study of local landscapes. Rather, the aim is to build models of the ecological niche requirements of a particular species within its native range with respect to factors that are available globally, to test whether these models can predict 
known occurrences of the species within its native range, and to use the models to forecast where on new landscapes conditions might be conducive to the establishment of populations. The point is not to model community interactions but to forecast invasion threats under the null model that no biotic factors prevent establishment of the species and given that community interactions can only be studied after the introduction and when it is usually too late to prevent establishment. In fact, the goal is not to understand the relationship between the biology of the species and the environmental data used to generate the models, although the models may clarify the relationship directly or indirectly and that is a matter for further study.

In this paper, we introduce such an approach to the problem of predicting invasive species in freshwater ecosystems. The analytical tool that we employ is the genetic algorithm for rule-set prediction (GARP); the ecological and environmental information comes from climatic and topographic data sets available worldwide; and the specimen records for native distribution are those readily available over the Internet, coupled with unpublished records of the species where they have already invaded. Herein we report applications of this approach, demonstrating accurate a posteriori prediction of a historical invasion and predicting possible consequences of a more recent invasion. In both cases, we emphasize the need to take action either to stop or to mitigate these invasions. The species in question are largemouth bass Micropterus salmoides and smallmouth bass M. dolomieu, and the landscapes are North America and the Japanese archipelago.

Approximately 300 species belonging to 145 genera and 53 families of freshwater fish are found in the Japanese archipelago. Japanese freshwater fishes include many native species in a wide variety of environments; indeed, although Japan is a small country, it has at least 52 endemic species and subspecies (Kawanabe and Mizuno 1989) and the latest Red List named 88 endangered species of freshwater fish (Japanese Ministry of the Environment 1999). More generally, island populations appear to be more prone to extinction than related continental populations (Smith et al. 1993; Frankham 1997).

Human activities such as introductions of nonnative species and pollutants are important causes of species extinction on islands (Williamson 1996). In fact, at least 26 species of nonnative freshwater fish have successfully invaded Japan through introductions both intentional and unin- tentional (Kawanabe and Mizuno 1989). International agreements have been struck to reduce the introduction and expansion of nonnative species (Bohn and Amundsen 2001).

One of the most damaging alien species in Japan is the largemouth bass, which has had impacts on populations of native aquatic organisms because of its role as a top predator (Shinya and Watanabe 1990; Maehata 1992). This North American fish was initially introduced into Lake Ashinoko in 1925 as a fisheries resource and was strictly confined to the lake until the 1960s, when sportfishing with lures became popular (Hosoya 1997). Illegal releases by anglers spread the species across Japan, and large populations are now established (Kawanabe and Mizuno 1989).

Genetic analyses of largemouth bass in Japan detected only two haplotypes in the NDI region of mitochondrial DNA (Kitagawa et al. 2000), suggesting that the fish were derived from a small founder pool. Introduced bass feed on a wide variety of aquatic organisms (e.g., fish, crustaceans, and insects), but individuals tend to shift to piscivory as they grow (Yoshizawa et al. 1980; Shinya and Watanabe 1990; Maehata 1992; Azuma and Motomura 1998; Yodo and Kimura 1998). Although growth rates vary among localities (Yodo and Kimura 1996), they fall within the ranges observed in North American populations (Bennet 1937; McCaig and Mullan 1960; Smagula and Adelman 1983). In invaded areas, largemouth bass have had serious impacts on local communities, causing a decrease in total fish biomass (Takahashi et al. 2001). Recently, the smallmouth bass has also been introduced into Japan, and successful reproduction has been confirmed in natural waters since the mid-1990s (Iguchi et al. 2001). Although little is known about the ecological aspects of smallmouth bass in nonnative habitats like Japan, the threat of this species to native populations of aquatic organisms is clear from their impact on a number of aquatic vertebrates in North and Middle America.

The largemouth bass ranks among the most important game fishes in North America. It is the largest bass (up to $11 \mathrm{~kg}$ ) and prefers clear, quiet waters with abundant aquatic vegetation (Scott and Crossman 1973; Carlander 1977; Lee 1980b). Although introductions have largely masked their native range, largemouth bass seem originally to have been distributed from northeastern Mexico north to southern Quebec and Ontario in the Mississippi River drainage, east to Florida, and along the Atlantic coast to central South Carolina (Hubbs 
and Lagler 1964; Carlander 1977; Lee 1980b; Page and Burr 1991). They are found in a variety of native habitats, do very well in artificial impoundments, and can tolerate higher turbidity than congeners. The largemouth bass is one of the most widely introduced fishes in the world, having been introduced into at least 60 countries worldwide (McDowall 1968; Robbins and MacCrimmon 1974; Carlander 1977) as well as throughout North America wherever suitable reservoirs are found (Lee 1980b). Carlander (1977) presented extensive life history data on the species, including data on introduced populations.

In contrast to largemouth bass, smallmouth bass prefer clear, fast-flowing streams and flowing pools with gravel bottoms (Lee 1980a) and were originally distributed from Minnesota and southern Quebec south to the Tennessee River drainage of Alabama and west to eastern Oklahoma (Hubbs and Lagler 1964; Carlander 1977). In terms of stream habitat, the smallmouth bass behaves as the northern equivalent of the spotted bass $M$. punctulatus and inhabits intermediate habitats when all three species are found sympatrically (i.e., certain streams in Ohio: Trautman 1981). Although smaller than the largemouth bass, its fighting qualities are appreciated by anglers. It has been introduced into 14 countries as well as into suitable habitat throughout nonnative portions of North America beginning in the 1850s (Carlander 1977). Its ability to extend its range without direct human introduction is demonstrated by its colonization of the Hudson River drainage after the opening of the Erie Canal in the 1820s (Hubbs and Bailey 1938).

As large, piscivorous predators, basses pose serious threats to native fish faunas (U.S. Geological Survey 2003). Both largemouth and smallmouth bass were introduced into California as early as 1874 (Emig 1966a, 1966b). In the western United States, introduced basses have been implicated in the decline of several species of minnow (tui chub Gila bicolor, roundtail chub G. robusta, Gila chub G. intermedia, White River spinedace Lepidomeda albivallis, relict dace Relictus solitarius, and speckled dace Rhinichthys osculus), pupfishes (Owens pupfish Cyprinodon radiosus and other Cyprinodon spp.), and one goodeid (White River spring fish Crenichthys baileyi) (Miller and Pister 1971; Minckley 1973). U.S. Fish and Wildlife Service recovery plans detail the impacts of these basses on other species (U.S. Fish and Wildlife Service 1985, 1994). Introduction of largemouth bass to Lake Atitlán, Guatemala, is implicated in the elimination of several native fishes, reduction of total fish biomass, and predation on and competition with the now-extinct Atitlán grebe Podilymbus gigas (LaBastille 1974). Introductions of smallmouth bass decreased populations of brown trout Salmo trutta and introduced bass tapeworms to species such as yellow perch Perca flavescens in Lake Opeongo, Ontario (Martin and Fry 1973). Smallmouth bass prey on juvenile Pacific salmonids and smolts in the Columbia River (Dentler 1993; Tabor et al. 1993) and are the most significant predator of Chinook salmon Oncorhynchus tshawytscha and wild steelhead $O$. mykiss subyearlings in reservoirs on the lower Snake River (Bennett 1998). Bass introductions have also been implicated in the declines of populations of the Chiricahua leopard frog Rana chiricahuensis and the California tiger salamander Ambystoma californiense in California and Arizona (Hayes and Jennings 1986; Rosen et al. 1995; Dill and Cordone 1997). Jenkins and Burkhead (1994) have speculated that bass introductions caused the extinction of an isolated population of trout-perch Percopsis omiscomaycus in Virginia.

Recent advances in modeling species' invasions (Peterson and Vieglais 2001) are now being applied to aquatic organisms. Bass invasions of Japan from North America provide an ideal test case, as distributional data are available for both native and invaded ranges, permitting quantitative assessment of model success or failure. Moreover, although largemouth bass are now well established in the southern islands of Japan, smallmouth bass are only beginning to establish populations there, leaving open the possibility that eradication is still feasible. Accurate distributional predictions could help to focus eradication efforts. Further, neither species is established in Hokkaido, and assessing the threat of both species to introduction into Hokkaido will provide decision makers with a threat assessment for that island. To that end, we develop ecological niche models for both species based on known native occurrences in North America, project them to Japan, and test the accuracy of the predictions using known occurrences in Japan.

\section{Methods}

Occurrence data for the two bass species in North America were obtained primarily from FishNet, a distributed biodiversity data resource providing access to natural history museum databases through the Species Analyst (http:// speciesanalyst.net); the institutions providing data include the University of Florida, Tulane University, the Museum of Comparative Zoology of Har- 
vard University, the University of Kansas Natural History Museum, the Illinois Natural History Survey, and the University of Michigan Museum of Zoology. We obtained 2,046 unique occurrence points for largemouth bass and 903 unique occurrence points for smallmouth bass within their presumed native ranges (summarized by Lee 1980a, 1980b). To reduce the bias caused by uneven point dispersal, we subsampled states with more than 100 unique records for largemouth bass by selecting 100 records at random, yielding a total of 1,085 points. From this pool, we selected 100 points at random and set them aside for testing the GARP models within the native range (extrinsic test data) and used 985 points in the modeling process (intrinsic training data). Smallmouth bass records were processed in a similar fashion except that only 50 points were included from each state that had more than 50 records, 50 records were reserved for testing as the extrinsic test data, and 607 points were used as intrinsic training data in the modeling process. For Japanese localities, occurrence points (634 for largemouth bass, 10 for smallmouth bass) were accumulated from annual reports on inland sportfishing (Nakama 1996; Okabe 2000) and were georeferenced using Zenrin (1998).

We used 10 ecological-environmental geographic data sets ("coverages") as the dimensions of the ecological niches to be modeled. Topographic and hydrologic data (elevation, slope, aspect, topographic index, flow accumulation, and flow direction) were obtained from the Hydro- $1 \mathrm{~K}$ data set (Land Processes DAAC 2003; 1-km spatial resolution raster coverages). ArcAtlas (ESRI 1996) supplied vector coverages summarizing average annual temperature and precipitation. Land use, land cover, and percent tree cover were obtained from the University of Maryland Global Land Cover Facility (2003). All coverages were clipped to the regions $23.5-51^{\circ} \mathrm{S}, 65-127^{\circ} \mathrm{W}$ (North America) and $26-47^{\circ} \mathrm{N}, 127-154^{\circ} \mathrm{E}$ (Japan) and gridded to a resolution of $0.01^{\circ}$ for analysis.

Ecological niches and potential geographic distributions were modeled with GARP (Stockwell and Noble 1992; Stockwell 1999; Stockwell and Peters 1999). In general, the procedure focuses on modeling ecological niches (i.e., the conjunction of ecological conditions within which a species is able to maintain populations: Grinnell 1917). Specifically, GARP relates the ecological characteristics of known occurrence points to those of points randomly sampled from the rest of the study region, seeking to develop a series of decision rules that best summarize the factors associated with the species' presence.
Initially, GARP divides the intrinsic training data mentioned above (e.g., the 1,085 points for largemouth bass) into two intrinsic data sets at a ratio specified by the investigator. One intrinsic set is used to generate rules (rule-generating data); the other is used to test the rules within each iteration (rule-testing data). It is important to note that these "intrinsic rule-testing data" are different from the extrinsic test data (e.g., the 100 points for largemouth bass) that are used to evaluate the overall outcome of the modeling process. The investigator can determine the ratio of intrinsic rule-generating and intrinsic rule-testing data; in these analyses, we used a ratio of 80:20 to maximize the number of points used for training while reserving an adequate number of points for testing.

The GARP procedure includes several distinct algorithms for niche modeling in an evolutionarycomputing environment. It works in an iterative process of rule selection, evaluation, testing, and incorporation or rejection. A rule is chosen from a set of possibilities (e.g., logistic regression and bioclimatic rules), applied to the intrinsic rulegenerating data, and allowed to evolve. Rules may evolve by a number of means that mimic DNA evolution: point mutations, deletions, crossing over, and so forth. Predictive accuracy is then evaluated on the basis of 1,250 points that are resampled (with replacement) from the pool of intrinsic rule-testing data and 1,250 points that are sampled randomly from the study region as a whole. The change in predictive accuracy from one iteration to the next is used to evaluate whether a particular rule should be incorporated into the model; the algorithm runs until it has either performed 1,000 iterations or achieved convergence (convergence is determined by a criterion specified by the investigator; we selected a default value of 0.01 ).

All of the modeling in this study was carried out via a desktop implementation of GARP (Scachetti-Pereira 2001). The algorithm's randomwalk process can produce many models that must then be evaluated to choose a "best-model" set (Anderson et al. 2003). The procedure is based on the observations that (1) models vary in quality, (2) variation among models involves an inverse relationship between errors of omission (leaving out the true distributional area) and commission (including areas not actually inhabited), and (3) the best models (as judged by experts who are blind to the error statistics) cluster in a region of minimum omission of independent test points and moderate area predicted (an axis related directly to commission error). Hence, among the 1,000 rep- 
TABLE 1.-Description of data used in a general algorithm for rule-set prediction model analysis, including the number of training points used to generate rule-set predictions in the native range (Train), the number of testing points used to test the models (Test), the number of testing points predicted by the intersection of all 10 models, 6-9 models, and 15 models, and the area under the curve (AUC), standard error (SE), and Z-score associated with receiver-operator curve analysis. Native range refers to the presumed native range of each species in North America; all habitats refers to the aggregation of Japanese records from specific habitats (lake, reservoir, etc.); $P<0.001$.*

\begin{tabular}{|c|c|c|c|c|c|c|c|c|}
\hline \multirow[b]{2}{*}{ Analysis } & \multirow[b]{2}{*}{ Train } & \multirow[b]{2}{*}{ Test } & \multicolumn{3}{|c|}{ Model subsets } & \multirow[b]{2}{*}{ AUC } & \multirow[b]{2}{*}{ SE } & \multirow[b]{2}{*}{$Z$} \\
\hline & & & 10 & $6-9$ & $1-5$ & & & \\
\hline \multicolumn{9}{|c|}{ Largemouth bass } \\
\hline Native range & 985 & 100 & 97 & 2 & 1 & 0.840 & 0.03 & $16.91^{*}$ \\
\hline \multicolumn{9}{|l|}{ Japan } \\
\hline All habitats & & 634 & 577 & 56 & 1 & 0.837 & 0.01 & $43.40^{*}$ \\
\hline Lake & & 43 & 32 & 11 & 0 & 0.801 & 0.04 & $10.38^{*}$ \\
\hline Reservoir & & 203 & 183 & 19 & 1 & 0.835 & 0.02 & $24.41 *$ \\
\hline Pond & & 247 & 225 & 22 & 0 & 0.837 & 0.02 & $27.06^{*}$ \\
\hline Creek & & 40 & 38 & 2 & 0 & 0.845 & 0.04 & $10.80 *$ \\
\hline River-stream & & 101 & 99 & 2 & 0 & 0.851 & 0.02 & $24.41 *$ \\
\hline \multicolumn{9}{|c|}{ Smallmouth bass } \\
\hline Native range & 607 & 50 & 50 & 0 & 0 & 0.967 & 0.02 & $12.05^{*}$ \\
\hline Japan & & 10 & 6 & 3 & 1 & $\mathrm{a}$ & & \\
\hline
\end{tabular}

licate models, we (1) eliminated all of the models with omission errors greater than zero (based on the internal test points), (2) calculated the median area in which species were predicted to be present (as a percentage of the area analyzed) among these zero-omission points, and (3) identified the 10 models closest to the overall median distributional area as the basis for further analysis. Ten models is the minimum number needed for further statistical tests.

The 10 best models were then tested using the original extrinsic testing data set (i.e., the 100 data points for largemouth bass and 50 data points for smallmouth bass) segregated from the native range occurrence points of each species. Each of the models was imported into ArcView (ESRI 1996), and the sum of the models visualized in geographic space as a mosaic of model intersections (Figure 1). That is, for any one area within North America, a particular pixel might carry the prediction that 10 models predict presence, that 5 models predict presence, or that no models predict presence. The extrinsic test data are overlain on the mosaic of models and evaluated through receiver-operator characteristic (ROC) analysis (Hanley and McNeil 1982; Centor 1991; Vida 1993). This analysis tests the sensitivity (a measure of omission error) and specificity (a measure of commission error) of the projected mosaic of models relative to their ability to successfully predict the presence of the extrinsic test data points (e.g., those 100 points withheld entirely from the modeling process for largemouth bass). In short, ROC scores are maximized for any particular set of models when all of the extrinsic data points fall into areas for which all 10 models have predicted species presence and are minimized when the extrinsic data points are as likely to be found where the models predict species absence as where they predict presence. Thus, if the models do no better than randomly predict the occurrence of the extrinsic test data, they will receive a score of 0.50 ; if the models do a perfect job of predicting the extrinsic test data points, they will receive a score that approaches 1.0 (mediated by the size of the landscape and the area of the landscape for which presence is predicted). The departure from randomness can be easily tested using the $Z$ statistic, yielding a test of model set accuracy.

To enable visualization of ecological niche models in geographic dimensions (i.e., as a map), GARP includes a module that projects rule-sets onto landscapes. Although the Web-based version (BIODI 2003) simply projects the rule-set onto the same coverages from which the model was developed, the desktop version permits projection to alternative landscapes as well. This step is key to predicting species' invasions, as multiple coverage sets can be included for visualization of areas fitting the model conditions (Peterson and Vieglais 2001). We projected the models onto the native distributional area to permit quantitative tests of 

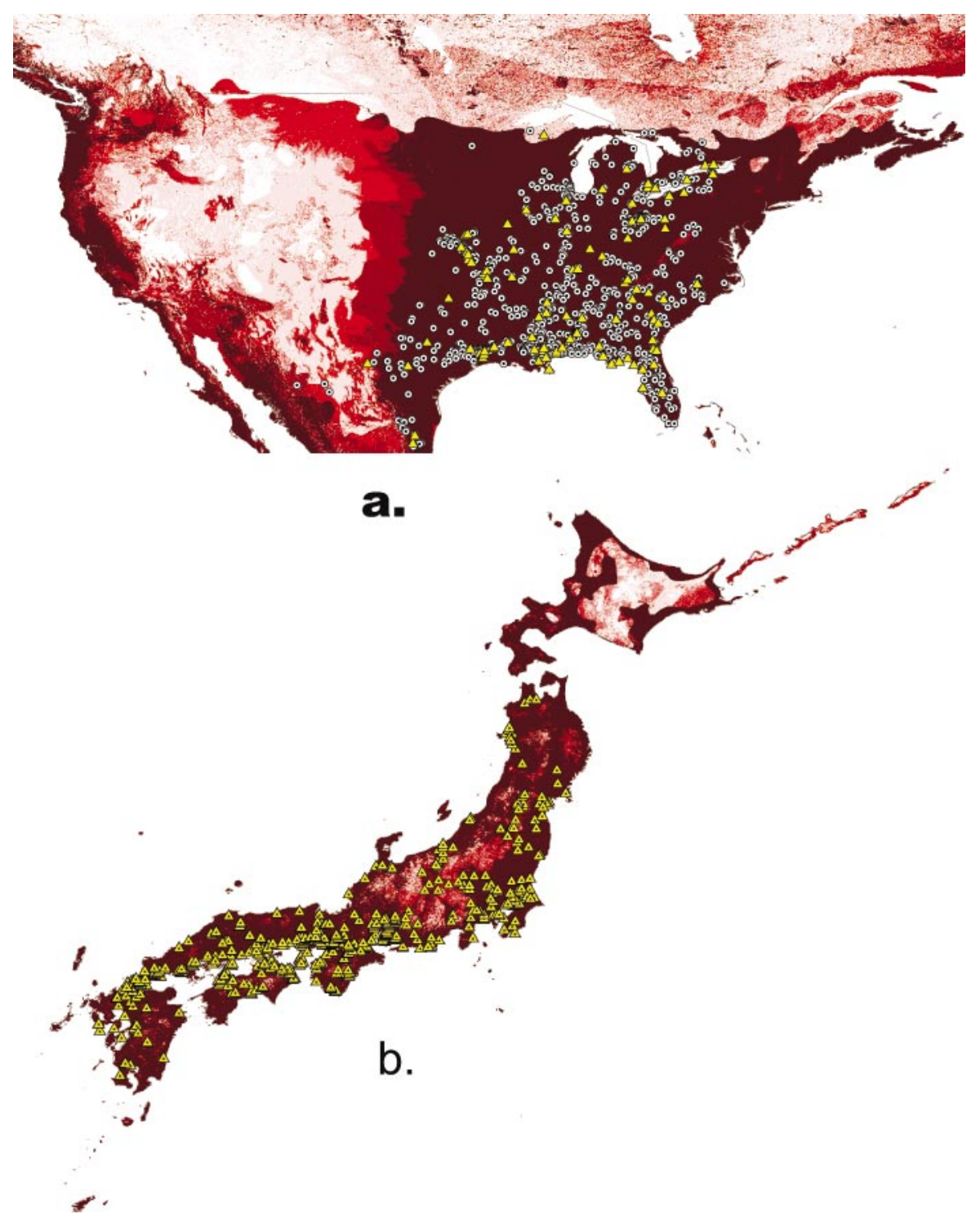

FIGURE 1.-Geographic predictions for largemouth bass in (a) North America and (b) Japan. White circles represent the intrinsic training data used to model the native distribution in North America. On the North American landscape, yellow triangles represent the extrinsic data used to test the native-range model; on the Japanese landscape, yellow triangles represent the known occurrences used to test the predicted geographic range. On both landscapes, pink to dark brown areas represent the intersection of various model sets, dark shades representing the intersection of all 10 models and light shades the intersection of fewer models. The maps are not to scale relative to each other.

model quality as well as onto Japan to predict species' potential ranges.

\section{Results}

\section{Largemouth Bass}

Visualization of the 10-best model set from the native range is shown in Figure 1a. The results were highly significant, 97 of 100 test points falling within the 10-model intersection (Table 1). Projecting the niche model onto Japan (Figure 1b) reveals that the species might be present over much of the landscape, including Hokkaido. Of the 634 test point occurrences from Japan, 577 were predicted by all 10 models, yielding a highly signif- 

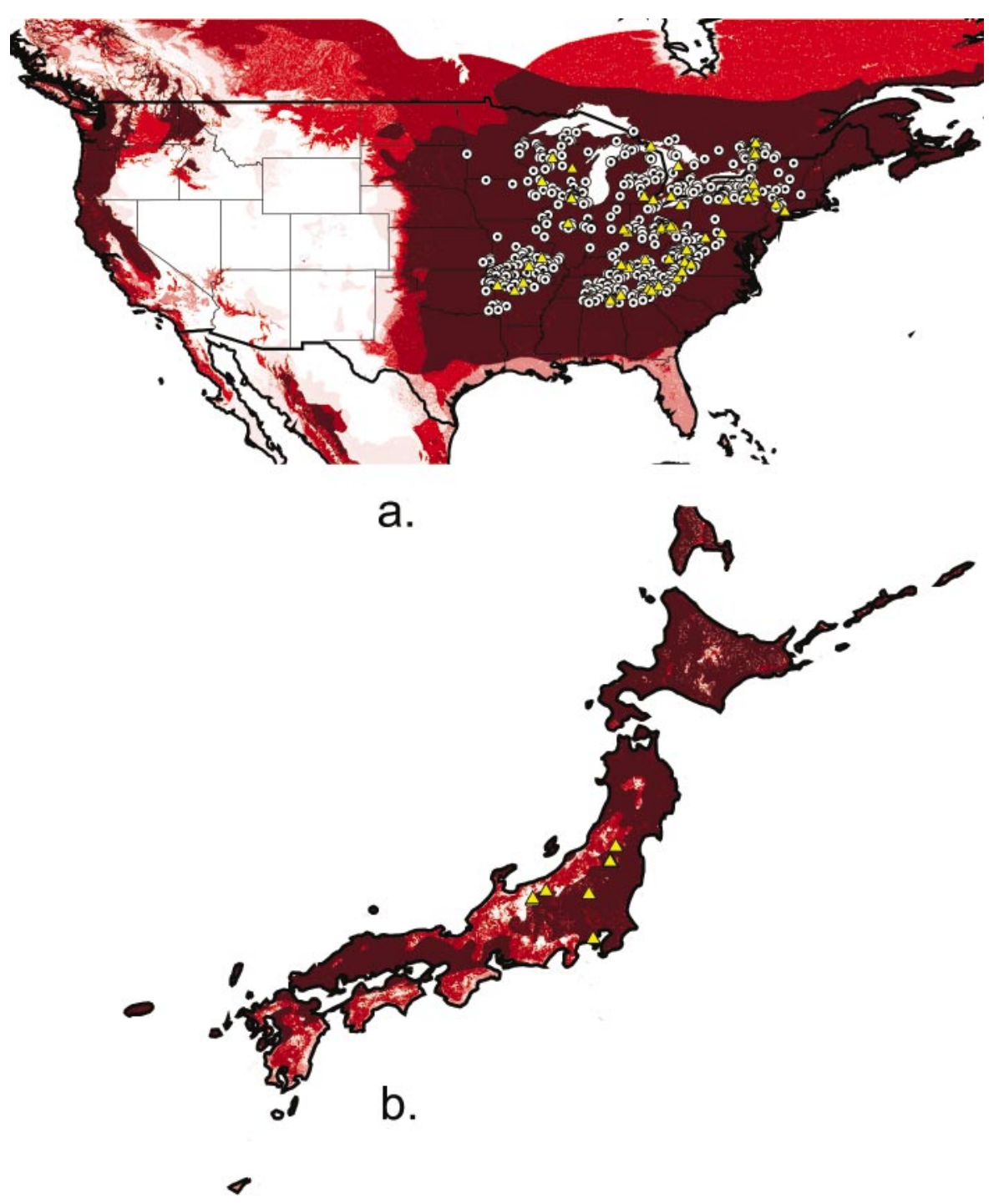

FIgURE 2.-Geographic predictions for smallmouth bass in (a) North America and (b) Japan. See the caption to Figure 1 for additional details.

icant prediction (Table 1) that was not significantly different from the ROC score received for test data drawn from the native range $(P>0.2149)$. The models also accurately predicted the Japanese points when they were parsed among the variety of habitats into which largemouth bass have been introduced (Table 1).

\section{Smallmouth Bass}

Visualization of the 10-best model set from the native range is shown in Figure 2a. All 50 extrinsic test data points were predicted by all 10 models, yielding an ROC area-under-the-curve score of 0.9667 ( $\mathrm{SE}=0.0178 ; Z=112.052 ; P<0.001)$. Projecting the niche model onto Japan (Figure 1b) reveals that the species would be present over much of the landscape, including Hokkaido. Of the 10 Japanese point occurrences that have been recorded, 6 were predicted by all 10 models while all of them were predicted by 5 or more models. We did not attempt an ROC analysis due to the low number of introduced occurrence points. All Japanese smallmouth bass test data points were drawn from lake samples. 


\section{Discussion}

The distributional areas predicted for largemouth bass in Japan showed excellent correspondence with known occurrences, and the statistical significance of the results indicates that our ecological niche model based on native-range North American occurrence points has excellent predictive ability. One might wonder why we modeled both species only in their native ranges rather than throughout their present North American range. There are two reasons. First, modeling only within the native range provides the most conservative assessment of the threat. Second, many potential invasive species are known only from their native ranges. To assess the utility of ecological modeling, it is important to demonstrate that modeling within a species' native range will yield accurate predictions of its ability to invade new areas. This study takes advantage of the introduction of two invasive species that affords the possibility of testing such predictions quantitatively. Unfortunately, largemouth bass have already occupied many potential habitats in the southern islands of Japan and are now widely distributed in the country. However, this species has not yet been introduced into the island of Hokkaido. Our results indicate that it is a potential threat there, and serious attention should be given to blocking its introduction.

Very few large, carnivorous fishes are native to Japanese freshwater habitats. A cyprinid, Opsariichthys uncirostris uncirostris, that is endemic to Lake Biwa feeds diurnally on fish (Tanaka 1964), and a catfish, Siurus asotus, and an eel Anguilla japonica, both widely distributed over the Japanese archipelago, forage on fish at night (Kobayakawa 1989; Tabeta 1989). Except for Opsariichthys, large, diurnal, carnivorous freshwater fishes are absent, providing an apparent ecological vacuum that is now filled by invasive largemouth bass.

Considering the predictive power of our models for largemouth bass, for which detailed tests were both possible and highly significant, our confidence in our prediction of the potential distributional areas for smallmouth bass in Japan is high. The present distribution of this species is limited to a few lakes and is much less extensive than the predicted area overall. This limited range probably results from its comparatively recent invasion.

The wide distribution of largemouth bass in Japan is apparently explicable by the numerous releases by sport anglers. Smallmouth bass com- monly occur in running water, which may indicate much better capacity for dispersal in Japan. Interestingly, largemouth bass that are introduced into lakes often decrease in numbers after the release of smallmouth bass (Iguchi and Yodo, unpublished data). Displacement of congener alien species may support the idea that lack of competitors had facilitated the invasion of alien species. However, this observation does not argue for the introduction of new alien species to compete with others; on the contrary, such an introduction would make the matter worse. Of particular interest is that the predictions for both basses include Hokkaido, yet neither has invaded there. Native salmonids are dominant there, however, and may either prevent alien invasions or be vulnerable to them, as they are in the Pacific Northwest of the United States (Tabor et al. 1993; Bennett 1998).

An important means of conserving native biodiversity is to prevent invasion by alien species. Once established, alien species are generally impossible to eliminate completely. Early detection of smallmouth bass invaders has made possible their eradication, as in Lakes Chuzenji and Motosu, where removal of individual fish was successful (Hideki Ohama, Yamanashi Prefectural Fisheries Technology Center, personal communication). Broad monitoring is needed to provide the early detections that make eradication of alien fishes possible. The present predictions are quite useful in this regard because they provide a strong basis on which to focus monitoring efforts.

\section{Acknowledgments}

Funding for this study was provided by the U.S. National Science Foundation (DEB-9985737), the Office of Naval Research (N0014-00-1-0887) through the Census of Marine Life/Ocean Biogeographic Information System Program, and the U.S. Geological Survey Caribbean Science Center. The Biodiversity Research Center, University of Kansas, provided the biodiversity informatics infrastructure that made this study possible.

\section{References}

Anderson, R. P., D. Lew, and A. T. Peterson. 2003. Evaluating predictive models of species' distributions: criteria for selecting best models. Ecological Modeling 162:211-232.

Azuma, M., and Y. Motomura. 1998. Feeding habits of largemouth bass in a non-native environment: the case of a small lake with bluegill in Japan. Environmental Biology of Fishes 52:379-389.

Bennett, D. H. 1998. So many predatory resident fishes: what needs to be done? Pages 197-202 in ODFW 
(Oregon Department of Fish and Wildlife) and NMFS (National Marine Fisheries Service). Management implications of co-occurring native and introduced fishes. ODFW and NMFS, Portland, Oregon.

Bennet, G. W. 1937. The growth of the large mouthed black bass, Huro salmoides (Lacepède), in the waters of Wisconsin. Copeia 1937:104-118.

BIODI (Biological Diversity). 2003. Available: http:// biodi.sdsc.edu.

Bohn, T., and P.-A. Amundsen. 2001. The competitive edge of an invading specialist. Ecology 82:21502163.

Carlander, K. D. 1977. Handbook of freshwater fishery biology, volume 2. Iowa State University Press, Ames.

Carlton, J. T. 1996. Pattern, process, and prediction in marine invasion ecology. Biological Conservation 78:97-106.

Centor, R. M. 1991. Signal detectability: the use of ROC curves and their analyses. Medical Decision Making 11:102-106.

Dentler, J. L. 1993. Noah's farce: the regulation and control of exotic fish and wildlife. University of Puget Sound Law Review 17:191-242.

Dill, W. A., and A. J. Cordone. 1997. History and status of introduced fishes in California, 1871-1996. California Department of Fish and Game, Fish Bulletin 178.

Emig, J. W. 1966a. Largemouth bass. Pages 332-353 in A. Calhoun, editor. Inland fisheries management. California Department of Fish and Game, Sacramento.

Emig, J. W. 1966b. Smallmouth bass. Pages 354-366 in A. Calhoun, editor. Inland fisheries management. California Department of Fish and Game, Sacramento.

Enserink, M. 1999. Biological invaders sweep in. Science 285:1834-1836.

ESRI (Environmental Systems Research Institute, Inc.). 1996. ArcAtlas. ESRI, Redlands, California.

Frankham, R. 1997. Do island populations have less genetic variation than mainland populations? $\mathrm{He}$ redity 78:311-327.

Grinnell, J. 1917. Field tests of theories concerning distributional control. American Naturalist 51:115128.

Hanley, J. A., and V. J. McNeil. 1982. The meaning and use of the area under a receiver operating characteristic (ROC) curve. Radiology 143:29-36.

Hayes, M. P., and M. R. Jennings. 1986. Decline of ranid frog species in western North America: are bullfrogs (Rana catesbeiana) responsible? Journal of Herpetology 20:490-509.

Hosoya, K. 1997. [Introduction of exotic species and biohazard.] Bulletin of the National Research Institute of Aquaculture Supplement 3:155-156. (In Japanese.)

Hubbs, C. L., and R. M. Bailey. 1938. The smallmouth bass. Cranbrook Institute of Science Bulletin 10:192.

Hubbs, C. L., and K. F. Lagler. 1964. Fishes of the Great
Lakes region, with a new preface. University of Michigan Press, Ann Arbor.

Iguchi, K., T. Yodo, and N. Matsubara. 2001. [Spawning habit of introduced smallmouth bass, Micropterus dolomieu.] Suisanzosyoku 49:157-160. (In Japanese with English summary.)

Japanese Ministry of the Environment. 1999. Red list of brackish and freshwater fishes in Japan. Japanese Ministry of the Environment, Tokyo.

Jenkins, R. E., and N. M. Burkhead. 1994. Freshwater fishes of Virginia. American Fisheries Society, Bethesda, Maryland.

Kawanabe, H., and N. Mizuno, editors. 1989. [Freshwater fishes of Japan.] YAMA-KEI Publishers, Tokyo. (In Japanese.)

Kitagawa, T., T. Okita, Y. Banno, S. Sugiyama, T. Okazaki, M. Yoshioka, and S. Kashiwagi. 2000. [Mitochondrial DNA of the Florida subspecies of largemouth bass Micropterus salmoides floridanus detected in Ikehara Reservoir, Nara Prefecture, Japan.] Nippon Suisan Gakkaishi 66:805-811. (In Japanese with English summary.)

Kobayakawa, M. 1989. Catfish. Pages 412-415 in H. Kawanabe and N. Mizuno, editors. [Freshwater fishes of Japan.] YAMA-KEI Publishers, Tokyo. (In Japanese.)

LaBastille, A. 1974. Ecology and management of the Atitlan Grebe, Lake Atitlan, Guatemala. Wildlife Monographs 37:1-66.

Lee, D. S. 1980a. Micropterus dolomieu. Page 608 in D. S. Lee et al., editors. Atlas of North American freshwater fishes. North Carolina State Museum of Natural History, Raleigh.

Lee, D. S. 1980b. Micropterus salmoides. Page 605 in D. S. Lee et al., editors. Atlas of North American freshwater fishes. North Carolina State Museum of Natural History, Raleigh.

Maehata, M. 1992. [Food habits of largemouth bass in the southern basin of Lake Biwa.] Annual Report of Biwako Bunkakan 10:1-8. (In Japanese.)

Martin, N. V., and F. E. J. Fry. 1973. Lake Opeongo: the ecology of the fish community and of man's effects on it. Great Lakes Fisheries Commission Technical Report 24:1-34.

McCaig, R. S., and J. W. Mullan. 1960. Growth of eight species of fishes in Quabbin Reservoir, Massachusetts, in relation to age of reservoir and introduction of smelt. Transactions of the American Fisheries Society 89:27-31.

McDowall, R. M. 1968. The proposed introduction of the largemouth black bass, Micropterus salmoides (Lacepède) into New Zealand. New Zealand Journal of Marine and Freshwater Research 2:149-161.

Miller, R. R., and E. P. Pister. 1971. Management of the Owens pupfish, Cyprinodon radiosus, in Mono County, California. Transactions of the American Fisheries Society 100:502-509.

Minckley, W. L. 1973. Fishes of Arizona. Sims Printing Company, Inc., Phoenix, Arizona.

Nakama, Y., editor. 1996. [Fishing places of bass and snakehead fish in 1996.] Gakken, Tokyo. (In Japanese.) 
Okabe, M., editor. 2000. [Fishing places of bass and snakehead fish in 2000.] Gakken, Tokyo. (In Japanese.)

Page, L. M., and B. M. Burr. 1991. A field guide to freshwater fishes. Houghton Mifflin, Boston.

Peterson, A. T., and D. A. Vieglais. 2001. Predicting species invasions using ecological niche modeling. BioScience 51:363-371.

Robbins, W. H., and H. R. MacCrimmon. 1974. The black bass in America and overseas. Biomanagement and Research Enterprise, Sault Ste. Marie, Ontario.

Rosen, P. C., C. R. Schwalbe, D. A. Parizek, Jr., P. A. Holm, and C. H. Lowe. 1995. Introduced aquatic vertebrates in the Chiricahua region: effects on declining native ranid frogs. Biodiversity and management of the Madrean Archipelago: the sky island of the southwestern United States and northwestern Mexico. U.S. Forest Service General Technical Report RM-GTR-264:251-261.

Scachetti-Pereira, R., 2001. Desktop GARP. Available: http://www.lifemapper.org/desktopgarp/. (October 2002.)

Scott, W. B., and E. J. Crossman. 1973. Freshwater fishes of Canada. Fisheries Research Board of Canada Bulletin 184:1-866.

Shinya, K., and S. Watanabe. 1990. [Feeding habit of adult largemouth bass, Micropterus salmoides, in the Ushiku-numa Lake in the central Honsyu.] Suisanzosyoku 38:245-252. (In Japanese with English summary.)

Smagula, C. M., and I. R. Adelman. 1983. Growth in a natural population of largemouth bass, Micropterus salmoides Lacepède, as determined by physical measurements and $\left[{ }^{14} \mathrm{C}\right]$-glycine uptake by scales. Journal of Fish Biology 22:695-703.

Smith, F. D. M., R. M. May, R. Pellew, G. J. A. Marshall, and P. R. Brown. 1993. How much do we know about the current extinction rate? Trends in Ecology and Evolution 8:375-378.

Stockwell, D. R. B. 1999. Genetic algorithms II. Pages 123-144 in A. H. Fielding, editor. Machine learning methods for ecological applications. Kluwer, Boston.

Stockwell, D. R. B., and I. R. Noble. 1992. Induction of sets of rules from animal distribution data: a robust and informative method of analysis. Mathematics and Computers in Simulation 33:385-390.

Stockwell, D. R. B., and D. P. Peters. 1999. The GARP modeling system: problems and solutions to automated spatial prediction. International Journal of Geographic Information Systems 13:143-158.

Tabeta, O. 1989. Eel. Pages 47-49 in H. Kawanabe and
N. Mizuno, editors. [Freshwater fishes of Japan.] YAMA-KEI Publishers, Tokyo. (In Japanese.)

Tabor, R. A., R. S. Shivley, and T. P. Poe. 1993. Predation on juvenile salmonids by smallmouth bass and northern squawfish in the Columbia River near Richland, Washington. North American Journal of Fisheries Management 13:831-838.

Takahashi, K., T. Onodera, and A. Kumagai. 2001. [Appearance of largemouth bass and changes in species composition of fish caught by set net at Izunuma and Uchnuma.] Miyagi Prefectural Reports of Fisheries Science 1:111-118. (In Japanese.)

Tanaka, S. 1964. The food and growth of "hasu" $O p$ sariichthys unicirostris (T. \& S.) in the Lake Biwa. Physiology and Ecology Japan 12:106-114.

Trautman, M. B. 1981. The fishes of Ohio. Ohio State University Press, Columbus.

University of Maryland Global Land Cover Facility. 2003. Available: http://glcf.umiacs.umd.edu/index. shtml.

U.S. Fish and Wildlife Service. 1985. Recovery plan for the Pahranagat roundtail chub, Gila robusta jordani. U.S. Fish and Wildlife Service, Portland, Oregon.

U.S. Fish and Wildlife Service. 1994. White River spinedace, Lepidomeda albivallis, recovery plan. U.S. Fish and Wildlife Service, Portland, Oregon.

U.S. Geological Survey. 2003. Nonindigenous Fish distributions information. Available: http://nas.er.usgs. gov/fishes/.

Vida, S. A. 1993. A computer program for nonparametric receiver operating characteristic analysis. Comparative Methods and Programs in Biomedicine 40:95-101.

Williamson, M. 1996. Biological invasions. Chapman and Hall, London.

Yodo, T., and S. Kimura. 1996. Age and growth of the largemouth bass Micropterus salmoides in Lakes Shorenji and Nishinoko, central Japan. Fisheries Science (Tokyo) 62:524-528.

Yodo, T., and S. Kimura. 1998. [Feeding habits of largemouth bass Micropterus salmoides in Lakes Shorenji and Nishinoko, central Japan.] Nippon Suisan Gakkaishi 64:26-38. (In Japanese with English summary.)

Yoshizawa, K., M. Takayanagi, S. Mogi, S. Kobayashi, K. Nobusawa, A. Sato, T. Ikeda, and M. Murata. 1980. [Resource ecological studies on a warm water piscivore, IV. Feeding ecology of largemouth bass in Lake Haruna.] Bulletin of Gumma Prefectural Fisheries Experimental Station 29:32-45. (In Japanese.)

Zenrin. 1998. [A software package for the Atlas of Japan.] Zenrin Co., Ltd., Tokyo. (In Japanese.) 